\title{
Blood Levels of Vitamin C, Carotenoids and Retinol Are Inversely Associated with Cataract in a North Indian Population
}

\author{
Mukesh Dherani, ${ }^{1}$ Gudlavalleti V. S. Murthy, ${ }^{2}$ Sanjeev K. Gupta, ${ }^{2}$ Ian S. Young, ${ }^{3}$ \\ Giovanni Maraini, ${ }^{4}$ Monica Camparini, ${ }^{4}$ Gill M. Price, ${ }^{1}$ Neena Jobn, ${ }^{2}$ \\ Usha Chakravartby, ${ }^{5}$ and Astrid E. Fletcher ${ }^{1}$
}

Purpose. To examine the association of blood antioxidants with cataract.

Methods. Cross-sectional study of people aged $\geq 50$ years identified from a household enumeration of 11 randomly sampled villages in North India. Participants were interviewed for putative risk factors (tobacco, alcohol, biomass fuel use, sunlight exposure, and socioeconomic status) and underwent lens photography and blood sampling. Lens photographs (nuclear, cortical, and posterior subcapsular) were graded according to the Lens Opacities Classification System (LOCS II). Cataract was defined as LOCS II grade $\geq 2$ for any opacity or ungradable, because of dense opacification or history of cataract surgery. People without cataract were defined as LOCS II $<2$ on all three types of opacity, with absence of previous surgery.

RESults. Of 1443 people aged $\geq 50$ years, 94\% were interviewed, $87 \%$ attended an eye examination, and $78 \%$ gave a blood sample; 1112 (77\%) were included in the analyses. Compared with levels in Western populations, antioxidants were low, especially vitamin C. Vitamin C was inversely associated with cataract. Odds ratios (OR) for the highest $(\geq 15 \mu \mathrm{mol} / \mathrm{L})$ compared with the lowest $(\leq 6.3 \mu \mathrm{mol} / \mathrm{L})$ tertile were 0.64 , (95\% confidence interval [CI] $0.48-0.85 ; P<0.01)$. Tertiles of zeaxanthin $(P<0.03), \alpha$-carotene $(P<0.05)$, and retinol $(P<$ $0.02)$ were associated with decreased odds of cataract. In analysis of continuous data, significant inverse associations were found for vitamin C, zeaxanthin, lutein, lycopene, $\alpha$ - and $\beta$-carotene, and $\beta$-cryptoxanthin, but not for $\alpha$ - or $\gamma$-tocopherol.

ConcLusions. Inverse associations were found between cataract and blood antioxidants in an antioxidant-depleted study

From the ${ }^{1}$ Department of Epidemiology and Population Health, London School of Hygiene and Tropical Medicine, London, United Kingdom; the ${ }^{2}$ Department of Community Ophthalmology, Dr. Rajendra Prasad Centre for Ophthalmic Sciences, All India Institute of Medical Sciences, New Delhi, India; the ${ }^{3}$ Centre for Clinical and Population Sciences and ${ }^{5}$ Ophthalmology and Vision Science, Queen's University Belfast, Northern Ireland, United Kingdom; and the ${ }^{4}$ Dipartimento di Scienze Otorino-Odonto-Oftalmologiche e Cervico Facciali, Sezione di Oftalmologia, Università degli Studi di Parma, Parma, Italy.

Supported by Wellcome Trust Grant 066082

Submitted for publication September 14, 2007; revised January 24 and April 9, 2008; accepted June 13, 2008.

Disclosure: M. Dherani, None; G.V.S Murthy, None; S.K. Gupta, None; I.S. Young, None; G. Maraini, None; M. Camparini, None; G.M. Price, None; N. John, None; U. Chakravarthy, None; A.E. Fletcher, None

The publication costs of this article were defrayed in part by page charge payment. This article must therefore be marked "advertisement" in accordance with 18 U.S.C. $\$ 1734$ solely to indicate this fact.

Corresponding author: Astrid E. Fletcher, Department of Epidemiology and Population Health, London School of Hygiene and Tropical Medicine, London, UK; astrid.fletcher@1shtm.ac.uk. sample. (Invest Ophthalmol Vis Sci. 2008;49:3328-3335) DOI: 10.1167/iovs.07-1202

$\mathrm{I}$ ndia accounts for a quarter of the global burden of blindness, with cataracts being the principal cause. ${ }^{1}$ Nearly all observational studies conducted to investigate risk factors for cataract have been performed in high-income countries, such as the United States or Australia, ${ }^{2}$ with some evidence supporting antioxidant vitamins as protective factors. Few research groups have investigated risk factors for cataracts in India, ${ }^{3-8}$ and in only one study in India was data collected on vitamin C. In that study, the results suggested that high levels of vitamin $\mathrm{C}$ were associated with increased risk of cataract. ${ }^{4}$ The present paper reports the associations of blood antioxidants and cataract from a study conducted in 2003 in North India.

\section{Subjects}

The INDEYE feasibility study was a population-based survey of persons living in a rural periurban region of Balbagarh, Faridabad district, serviced by a community outreach hospital of the All India Institute of Medical Sciences, New Delhi. The purpose of the feasibility study was to test the acceptability of the study (in particular, response rates to blood collection) and obtain estimates of lens opacities and age-related macular degeneration for a future larger study. The study methods have been described in detail elsewhere. ${ }^{9}$ A list of villages was obtained from the 1991 census data (2001 census data were not available at that time), and 11 villages were randomly selected on the basis that $13 \%$ of the population would be aged $\geq 50$ years. Recruitment into the study was performed between September 2002 and January 2003. People aged $\geq 50$ years were enumerated through a door-to-door household survey and invited to take part in the study. The study adhered to the guidelines in the Declaration of Helsinki. Before enumeration, meetings were held with local village leaders to explain the study objectives and methods. Participants who were illiterate had the information leaflet read to them and were enrolled in the study only after informed written consent (for illiterate participants, a thumb impression was accepted as a signature) was obtained. The study received ethics approval from the Research Ethics Committees of the All India Institute of Medical Sciences, the London School of Hygiene and Tropical Medicine, and the Queen's University of Belfast.

\section{Methods}

Participants completed a structured questionnaire and attended a clinical examination. The questionnaire was administered at participants' homes by trained fieldworkers (graduate nutritionists) and included information on sociodemographic and economic characteristics including age, sex, current and past jobs, literacy, landholding, household cooking practices (types of cooking fuels and stoves used), and both current and past smoking and alcohol use. Literacy was ascer- 
tained by asking "can you read and write." For smoking, we asked about current and past use, the type and amount of smoking: Western style cigarettes (number daily), Indian cigarettes or bidis (number daily), and pipe or huqa (amount of tobacco daily). Alcohol questions included information on type of alcohol, (desi, a locally made Indian spirit; foreign, i.e., non-Indian spirits; and homemade alcohol), frequency of drinking and drinking in the past. Sunlight exposure was ascertained by asking people about their occupations and the number of hours spent outdoors (all day and middle of the day) both currently and in the past. The clinical examination took place at a local outreach hospital and included visual acuity, measurement of weight, height, and blood pressure, with an automated device (HEM 705CP; Omron Healthcare, Inc., Bannockburn, IL; two measurements each of systolic and diastolic pressure in the sitting position after 5 minutes' rest and with the second measurement taken after a further period of 5 minutes), lens and fundus photography, and collection of blood samples. At the clinical visit the participants were asked about use of any medications or nutritional supplements (locally described as tonics).

\section{Lens Photography and Grading}

The detailed procedures for lens photography and grading of the type and severity of lens opacities is described elsewhere. ${ }^{9}$ Two different systems were used to obtain lens images after attaining a pupillary dilation of at least $6 \mathrm{~mm}$ (Neitz CT-S; Kowa Optimed Inc., Torrance, CA) for acquiring noncolored digital retroillumination images (two for each eye, one focused on the anterior and the other on the posterior lens surface) to capture cortical and posterior subcapsular opacities and a slit lamp (model SL-7E; Topcon Corp., Tokyo, Japan) for acquiring color slide photographic images to capture nuclear opacities. The Lens Opacity Classification System II (LOCS II) ${ }^{10}$ was used to classify the lens opacities by type and severity of cataract. Lens photography and grading were undertaken by two optometrists who were trained and certified for these procedures by the grading center in the University of Parma, Parma, Italy (GM, MC).

A 15-mL sample of blood was collected in a dimly lit room from each participant in two different collection tubes $10 \mathrm{~mL}$ clotted and 5 mL unclotted (Vacutainer; BD Biosciences, San Diego, CA). The 10-mL blood sample was kept at room temperature for 1 hour to allow for adequate clotting. The unclotted blood sample was kept in the refrigerator. Both samples were centrifuged at $3000 \mathrm{rpm}$ at $3^{\circ} \mathrm{C}$ (using a cold centrifuge) and stored in the refrigerator. The serum from the clotted sample and plasma from the unclotted sample were transported each evening in a vaccine container packed with dry ice to the study center (Dr. Rajendra Prased Centre, New Delhi, India), where they were stored in a $-80^{\circ} \mathrm{C}$ freezer. Samples were subsequently shipped in dry ice to the Queen's University Belfast for analysis by reversed-phase HPLC for serum lutein, zeaxanthin, $\beta$-cryptoxanthin, $\alpha$-carotene, $\beta$-carotene $\alpha$-tocopherol, $\gamma$-tocopherol, lycopene, and retinol. Total plasma ascorbate was measured with an enzyme-based assay in plasma stabilized with metaphosphoric acid. Cholesterol was measured with an enzymatic assay (Randox, Crumlin, UK) on a centrifugal analyzer (Cobas FARA; Roche Diagnostics, Burgess Hill, West Sussex, UK).

\section{Statistical Analysis}

Cataract was classified according to the worse grade of opacity in either eye and was defined as an opacity grade on LOCS II of $\geq 2$ for nuclear, cortical, or posterior subcapsular (PSC) cataract. People with bilateral dense opacities that could not be graded for type of cataract were included in additional analyses of any type of lens opacities, and people who were bilaterally aphakic or pseudophakic were included in further models. People with unilateral aphakia or pseudophakia or dense opacities were included in the analysis for "all cataracts" and in the analysis for type of cataract if the other eye could be graded for opacity. Blood antioxidants were categorized in thirds. In addition, because serum tocopherols are lipid soluble, we calculated the ratio of serum $\alpha$ - and $\gamma$-tocopherol to cholesterol and categorized in thirds. To examine the effect of blood antioxidants as continuous variables, we used a $\log _{\mathrm{e}}$ transformation, as transformation was optimal for normalizing the distribution. Body mass index (BMI: weight in kilograms/ [height in meters $\left[{ }^{2}\right.$ ) was categorized according to World Health Organization definitions ${ }^{11}$ (underweight, $<18.5$; normal weight, $\geq 18.5$ to $<25$; overweight, $\geq 25$ to $<30$; and obese, $\geq 30 \mathrm{BMI}$ ). We calculated cumulative working lifetime midday sun exposures from the number of hours spent outside at midday and expressed as a proportion of the maximum potential midday hours of exposure of an individual of a given age. Since less than $5 \%$ of households used clean cooking fuels (such as bottled gas, electricity, or kerosene), we were unable to include cooking fuels in the analysis. The potential confounders entered into models included age (continuous), sex, smoking (current, former, or never), alcohol consumption (current, former, or never), literacy (illiterate or not illiterate), landholding (no land or some land), midday sunlight exposure (tertiles), systolic blood pressure (average of two readings), and BMI (the four categories described).

Statistical analysis was performed with commercial software (STATA $9^{12}$ ). All analyses took account of the study design (11 study villages) by using the software survey commands in the estimation of standard errors and corresponding probabilities and 95\% confidence intervals (CIs). In all analyses, the comparison group was those without cataract, defined as LOCS II $<2$ on all three types of opacity in the worse eye and without dense opacities or clinical evidence of surgery in either eye. For univariable analyses, design-based Pearson's statistics were used for comparison of categorical variables and linear estimation for comparison of means. Multivariable survey logistic regression was used to investigate the association of antioxidants with any cataract and by type of cataract after adjustment for confounders. We used design-adjusted Wald tests for differences between the tertiles of each antioxidant, with the three categories entered as independent variables. To test for trend across tertiles, we replaced the independent variables with the three categories as a continuous measure and designadjusted Wald tests used. In analyses of continuous antioxidants we used design-adjusted Wald tests and, to aid interpretation we estimated the odds ratios and 95\% confidence intervals associated with a doubling in antioxidant level through "lincom" commands.

\section{Results}

Subjects aged $\geq 50$ years or over $(n=1443 ; 52 \%$ females) were enumerated, of whom 1260 (87.3\%) attended the clinical examination; $90 \%(n=1130)$ of these gave a blood sample. Blood samples were not analyzable in 14 people, and 4 people who attended the clinical examination did not have a lens assessment or photography. The number of people with data on blood and clinical data was 1112 (77\%). Compared with nonresponders to the clinic examination and those without usable data, people with usable data were younger (mean age, 61.7 years compared with $65.6, P<0.01$ ) but there were no differences in sex, literacy, or landholding. Compared with those who attended the clinical examination but did not have usable data, those with usable data were younger (61.7 years compared with 70.1 years, $P<0.001$ ), more likely to be male ( $42.8 \%$ compared with $35.8 \%, P<0.01$ ), and less likely to be illiterate $(82.4 \%$ compared with $68.7 \%, P<0.01)$, but there were no differences in landholding, smoking, outdoor exposure, or BMI. The higher proportion of illiterate participants who did not have usable data was explained by differences in age and sex.

Several antioxidants correlated highly: zeaxanthin with lutein $(r=0.79)$; both lutein and zeaxanthin $(r=0.5-0.7)$ with $\alpha$-carotene, $\beta$-carotene, lycopene, and $\alpha$-tocopherol, and less strongly with retinol $(r=0.4-0.5)$; and $\alpha$ - and $\beta$-carotene with each other $(r=0.65)$ and with lycopene $(r>0.7)$. Vitamin $C$ correlated less strongly with other antioxidants, apart from $\beta$-cryptoxanthin $(r=0.34)$. With the exception of $\gamma$-tocopherol and $\beta$-carotene, the antioxidants were inversely associated 
with age. In age-adjusted analyses, antioxidants were higher in females for vitamin $\mathrm{C}(P<0.001)$, lutein $(P<0.05)$, $\gamma$-tocopherol ratio $(P<0.01)$, and cholesterol $(P<0.001)$, whereas the $\alpha$-tocopherol ratio $(P<0.01)$ and retinol $(P<0.001)$ were higher in males. In age- and sex-adjusted analyses, BMI was inversely related to $\beta$-carotene $(P=0.01)$ and lycopene $(P=$ $0.02)$ and positively associated with retinol $(P<0.001), \alpha$ - and $\gamma$-tocopherol $(P<0.001$ for both), and cholesterol $(P<$ $0.001)$. In age- and sex-adjusted analyses, smoking was significantly related to vitamin $\mathrm{C}$, with current smokers having the lowest levels and never-smokers the highest; smoking was not associated with other antioxidants. Any use of a nutritional supplement was reported by only two of the participants (both were taking vitamin B12 complex and in one, the B12 complex was enriched with vitamin $\mathrm{C}$ ).

The prevalence of lens opacities have been described in detail $^{9}$ and were essentially similar in those with usable data on blood antioxidants and potential confounders: 578 (56.7\%) had nuclear cataracts, $221(21.8 \%)$ cortical cataracts, and 208 (20.5\%) PSC opacities. Most PSC and cortical cataracts were mixed; pure opacities occurred in 311 nuclear, 47 cortical, and 14 PSC cataracts. Of all subjects, 763 had any type of cataract, including dense opacities and including people who had undergone cataract surgery, 821 were classified as having a cataract $(74.2 \%, 95 \%$ CI $70.1 \%-78.3 \%) ; 291$ people had no cataracts (i.e., were graded as $<2$ on all three types of opacities), were without dense opacities, and had not had surgery. In univariable analyses, compared with those without cataract, people with cataract were older and were more likely to be illiterate, to have lower BMIs, and to have higher systolic blood pressure (Table 1). Antioxidants were significantly lower in people with cataract for all antioxidants except $\gamma$-tocopherol. In multivariable logistic regression, alcohol consumption, literacy, landholding, or midday sunlight exposure were not associated with cataract or specific types of cataract and were not included in further models. In the results by tertile of antioxidant distribution, vitamin C, zeaxanthin, $\alpha$-carotene, $\alpha$-tocopherol (but not the ratio of $\alpha$-tocopherol to cholesterol) and retinol were inversely associated with cataract (Table 2 ). In the analysis of antioxidants as continuous variables, there were significant associations for all antioxidants except $\alpha$ - or $\gamma$-tocopherol. There was no significant interaction with smoking and vitamin $\mathrm{C}$ in the association with cataract. The highest tertile of plasma vitamin $\mathrm{C}$ was significantly inversely associated with all three types of cataract (Table 3).

\section{Discussion}

We found associations between blood antioxidants and cataract in a rural Indian population. To our knowledge, relationships between blood or dietary measures of antioxidants and cataracts have not been reported before in India or other low-income countries. There have been two randomized trials of multivitamin supplements in low-income countries, one in China ${ }^{13}$ and one in India, ${ }^{14}$ which are discussed later in this

TABLE 1. Characteristics of People with and without Cataract

\begin{tabular}{|c|c|c|c|}
\hline & $\begin{array}{l}\text { Cataract* } \\
(n=821)\end{array}$ & $\begin{array}{l}\text { No Cataract } † \\
\quad(n=291)\end{array}$ & $P \ddagger$ \\
\hline Age $(y) \int$ & $64.0(8.8)$ & $55.0(4.7)$ & $<0.001$ \\
\hline Males\| & $402(49.0)$ & $134(46.1)$ & 0.4 \\
\hline Illiterate\| & $594(72.4)$ & $170(58.4)$ & 0.02 \\
\hline No land\| & 254 (30.9) & $80(27.5)$ & 0.3 \\
\hline \multicolumn{4}{|c|}{ Smoking (data missing in 30 with cataract and 12 without cataract) $\|$} \\
\hline Never & $201(25.4)$ & $86(30.8)$ & \\
\hline Ex & $91(11.5)$ & $20(7.2)$ & 0.1 \\
\hline Current & $499(63.1)$ & $173(62.0)$ & \\
\hline \multicolumn{4}{|c|}{$\begin{array}{l}\text { Categories of BMI }\left(\mathrm{kg} / \mathrm{m}^{2}\right) \text { (data missing in } 13 \text { with cataract and } 4 \\
\text { without cataract) } \|\end{array}$} \\
\hline$<18.5$ & $258(31.9)$ & $62(21.6)$ & \\
\hline$\geq 18.5$ to $<25$ & $441(54.6)$ & $155(54.0)$ & 0.01 \\
\hline$\geq 25$ to $<30$ & $95(11.7)$ & $58(20.2)$ & \\
\hline$\geq 30$ & $14(1.7)$ & $12(4.2)$ & \\
\hline \multicolumn{4}{|c|}{ Highest tertile of midday outdoor exposure (data missing in 30 with } \\
\hline cataract and 12 without cataract) $\|$ & $279(35.3)$ & $88(31.5)$ & 0.4 \\
\hline Systolic blood pressure (mm HG) $\mathbb{1}$ & $141.5(27.7)$ & $132.8(24.9)$ & $<0.001$ \\
\hline \multicolumn{4}{|l|}{ Blood measurements $(\mu \mathrm{mol} / \mathrm{L}) \mathbb{S}$} \\
\hline Vitamin C & $13.7(13.75)$ & $19.11(17.20)$ & $<0.001$ \\
\hline Lutein & $0.101(0.053)$ & $0.114(0.060)$ & 0.003 \\
\hline Zeaxanthin & $0.020(0.013)$ & $0.023(0.015)$ & 0.003 \\
\hline$\beta$-Cryptoxanthin & $0.009(0.008)$ & $0.012(0.015)$ & 0.02 \\
\hline$\alpha$-Carotene & $0.017(0.015)$ & $0.020(0.016)$ & 0.02 \\
\hline$\beta$-Carotene & $0.148(0.152)$ & $0.172(0.166)$ & 0.01 \\
\hline Lycopene & $0.305(0.335)$ & $0.354(0.368)$ & 0.02 \\
\hline$\alpha$-Tocopherol & $19.20(5.16)$ & $20.63(5.37)$ & 0.01 \\
\hline$\gamma$-Tocopherol & $2.53(0.92)$ & $2.54(0.84)$ & 0.8 \\
\hline$\alpha$-Tocopherol:cholesterol & $4.23(1.04)$ & $4.44(1.13)$ & 0.03 \\
\hline$\gamma$-Tocopherol:cholesterol & $0.56(0.19)$ & $0.55(0.18)$ & 0.5 \\
\hline Retinol & $1.74(0.65)$ & $1.95(0.66)$ & 0.001 \\
\hline Cholesterol & $4.63(1.09)$ & $4.72(0.95)$ & 0.2 \\
\hline
\end{tabular}

* Cataract defined as LOCS II $\geq 2$ for any specific cataract or dense opacity or aphakic/pseudophakic.

† No cataract defined as people with LOCS II $<2$ on PSC, cortical and nuclear opacities, no dense opacities, and no history of surgery in either eye

$\ddagger P$ for differences in univariable analysis between those with and without cataract.

$\int$ Mean (SD).

|| Proportion (\%). 
TABLE 2. Association of Antioxidants with Cataract*

\begin{tabular}{|c|c|c|c|c|c|}
\hline Antioxidant & Tertile & ORt & 95\% CI & $P S$ & $\boldsymbol{P} \|$ \\
\hline \multirow[t]{4}{*}{ Ascorbate $(\mu \mathrm{mol} / \mathrm{L})$} & $<6.5$ & 1 & & & \\
\hline & $\geq 6.5$ to $<15.4$ & 0.60 & $0.39-0.91$ & 0.02 & 0.01 \\
\hline & $\geq 15.4$ & 0.64 & $0.48-0.85$ & 0.005 & \\
\hline & $\log _{e} \#$ & 0.86 & $0.75-0.99$ & 0.04 & \\
\hline \multirow[t]{4}{*}{ Lutein $(\mu \mathrm{mol} / \mathrm{L})$} & $<0.0762$ & 1 & & & \\
\hline & $\geq 0.0762$ to $<0.1137$ & 0.70 & $0.43-1.15$ & 0.1 & 0.06 \\
\hline & $\geq 0.1137$ & 0.66 & $0.43-1.02$ & 0.06 & \\
\hline & $\log _{\mathrm{e}} \#$ & 0.73 & $0.60-0.89$ & 0.01 & \\
\hline \multirow[t]{4}{*}{ Zeaxanthin $(\mu \mathrm{mol} / \mathrm{L})$} & $<0.0155$ & 1 & & & \\
\hline & $\geq 0.0155$ to $<0.0214$ & 0.71 & $0.44-1.15$ & 0.1 & 0.03 \\
\hline & $\geq 0.0214$ & 0.66 & $0.45-0.96$ & 0.04 & \\
\hline & $\log _{\mathrm{e}} \#$ & 0.75 & $0.64-0.87$ & 0.002 & \\
\hline \multirow[t]{4}{*}{$\beta$-Cryptoxanthin $(\mu \mathrm{mol} / \mathrm{L})$} & $<0.0063$ & 1 & & & \\
\hline & $\geq 0.0063$ to 0.0095 & 0.75 & $0.39-1.43$ & 0.3 & 0.5 \\
\hline & $\geq 0.0095$ & 0.88 & $0.63-1.23$ & 0.4 & \\
\hline & $\log _{e} \#$ & 0.76 & $0.61-0.96$ & 0.02 & \\
\hline \multirow[t]{4}{*}{$\alpha$-Carotene $(\mu \mathrm{mol} / \mathrm{L})$} & $<0.0110$ & 1 & & & \\
\hline & $\geq 0.0110$ to $<0.0198$ & 0.58 & $0.38-0.89$ & 0.02 & 0.05 \\
\hline & $\geq .0198$ & 0.69 & $0.50-0.95$ & 0.03 & \\
\hline & $\log _{e} \#$ & 0.87 & $0.77-0.98$ & 0.02 & \\
\hline \multirow[t]{4}{*}{$\beta$-Carotene $(\mu \mathrm{mol} / \mathrm{L})$} & $<0.0849$ & 1 & & & \\
\hline & $\geq 0.0849$ to 0.1479 & 0.91 & $0.50-1.66$ & 0.7 & 0.3 \\
\hline & $\geq 0.1479$ & 0.77 & $0.45-1.32$ & 0.3 & \\
\hline & $\log _{e^{\#}}$ & 0.86 & $0.75-0.98$ & 0.03 & \\
\hline \multirow{4}{*}{ Lycopene $(\mu \mathrm{mol} / \mathrm{L})$} & $<0.1638$ & 1 & & & \\
\hline & $\geq 0.1638$ to $<0.3203$ & 1.13 & $0.70-1.83$ & 0.6 & 0.2 \\
\hline & $\geq 0.3203$ & 0.78 & $0.49-1.23$ & 0.3 & \\
\hline & $\log _{\mathrm{e}} \#$ & 0.88 & $0.77-0.99$ & 0.05 & \\
\hline \multirow[t]{4}{*}{$\alpha$-Tocopherol $(\mu \mathrm{mol} / \mathrm{L})$} & $<17.02$ & 1 & & & \\
\hline & $\geq 17.02$ to $<20.84$ & 0.91 & $0.69-1.20$ & 0.5 & 0.04 \\
\hline & $\geq 20.84$ & 0.58 & $0.36-0.94$ & 0.03 & \\
\hline & $\log _{\mathrm{e}} \#$ & 0.58 & $0.30-1.18$ & 0.1 & \\
\hline \multirow[t]{4}{*}{$\gamma$-Tocopherol $(\mu \mathrm{mol} / \mathrm{L})$} & $<2.07$ & 1 & & & \\
\hline & $\geq 2.07$ to $<2.71$ & 1.27 & $0.93-1.73$ & 0.1 & 0.06 \\
\hline & $\geq 2.71$ & 0.75 & $0.57-0.98$ & 0.04 & \\
\hline & $\log _{e^{\#}}$ & 0.81 & $0.51-1.27$ & 0.3 & \\
\hline \multirow[t]{4}{*}{$\alpha$-Tocopherol:cholesterol ratio } & $<3.83$ & 1 & & & \\
\hline & $\geq 3.83$ to $<4.46$ & 0.82 & $0.61-1.11$ & 0.2 & 0.2 \\
\hline & $\geq 4.46$ & 0.70 & $0.42-1.16$ & 0.1 & \\
\hline & $\log _{\mathrm{e}} \#$ & 0.61 & $0.31-1.20$ & 0.1 & \\
\hline \multirow[t]{4}{*}{$\gamma$-Tocopherol: cholesterol ratio } & $<0.457$ & 1 & & & \\
\hline & $\geq 0.457$ to $<0.595$ & 1.13 & $0.85-1.51$ & 0.4 & 0.4 \\
\hline & $\geq 0.595$ & 0.86 & $0.60-1.24$ & 0.4 & \\
\hline & $\log _{\mathrm{e}} \#$ & 0.87 & $0.53-1.42$ & 0.5 & \\
\hline \multirow[t]{4}{*}{ Retinol $(\mu \mathrm{mol} / \mathrm{L})$} & $<1.47$ & 1 & & & \\
\hline & $\geq 1.47$ to $<1.96$ & 0.83 & $0.58-1.19$ & 0.3 & 0.02 \\
\hline & $\geq 1.96$ & 0.58 & $0.37-0.91$ & 0.02 & \\
\hline & $\log _{\mathrm{e}} \#$ & 0.61 & $0.40-0.93$ & 0.03 & \\
\hline
\end{tabular}

* 778 people with cataract (LOCS II $\geq 2$ for any specific cataract or bilateral dense opacity or aphakic/pseudophakic compared to 276 without cataract (defined as LOCS II $<2$ on PSC, cortical and nuclear opacities, no dense opacities and no history of operation in either eye) and complete data on antioxidants, cholesterol, smoking, BMI and systolic blood pressure

† OR adjusted for age, sex, smoking, BMI, and average systolic blood pressure.

$\neq 95 \% \mathrm{CI}$

$\S P$ for effect of each third compared to the lower third.

$\| P$ for trend across tertiles.

\# Modeled as the odds ratio for a doubling of the natural log of the antioxidant level.

section. Similar to other studies in India, the prevalence of cataract was very high in our study. ${ }^{15}$ Blood antioxidants were low in our study population compared with studies in Western populations. ${ }^{16}$ In particular, vitamin $\mathrm{C}$ levels were extremely low, with mean levels of $13.0 \mu \mathrm{mol} / \mathrm{L}$ in the males and 17.1 $\mu \mathrm{mol} / \mathrm{L}$ in the females in our study compared with $54 \mu \mathrm{mol} / \mathrm{L}$ in the males and $64 \mu \mathrm{mol} / \mathrm{L}$ in the females in European populations. ${ }^{16}$ Although there are few comparative data on plasma antioxidants from any studies in India, low plasma vitamin C has been reported in a population study of males and females aged 20 to 50 years from western India in whom the mean plasma vitamin C was $18 \mu \mathrm{mol} / \mathrm{L} ; 74 \%$ had levels below 22.7 $\mu \mathrm{mol} / \mathrm{L} .{ }^{17}$ This contrasts with the data from Indian populations resident in Singapore in whom the mean plasma vitamin $\mathrm{C}$ was $\sim 30 \mu \mathrm{mol} / \mathrm{L} .{ }^{18}$ Blood carotenoids in our study were also lower than those reported in Western populations. ${ }^{16,19}$ In the EPIC (European Prospective Investigation into Cancer and Nutrition) study mean plasma zeaxanthin ranged from 0.11 to 0.13 $\mu \mathrm{mol} / \mathrm{L}$ in Mediterranean countries to $\sim 0.06 \mu \mathrm{mol} / \mathrm{L}$ in northern Europe ${ }^{19}$ compared with $0.02 \mu \mathrm{mol} / \mathrm{L}$ in our study. Retinol levels in our study (mean of $1.8 \mu \mathrm{mol} / \mathrm{L}$ ) were higher than those reported in one study in India $(0.87 \mu \mathrm{mol} / \mathrm{L})$ and slightly lower than that reported in Europe (mean, $2.15 \mu \mathrm{mol} / \mathrm{L}$ in males and $1.91 \mu \mathrm{mol} / \mathrm{L}$ in females). ${ }^{16,20}$ 
Table 3. Association of Antioxidants with Type-Specific Cataract

\begin{tabular}{|c|c|c|c|c|c|c|c|c|c|c|c|c|c|}
\hline \multirow[b]{2}{*}{ Antioxidant $(\mu \mathrm{mol} / \mathrm{L})$} & \multirow[b]{2}{*}{ Tertile } & \multicolumn{4}{|c|}{$\begin{array}{c}\text { Nuclear Cataract } 554 \text { with } \\
\text { Cataract* vs. } 272 \\
\text { with No Cataract } †\end{array}$} & \multicolumn{4}{|c|}{$\begin{array}{c}\text { Cortical Cataract } 208 \text { with } \\
\text { Cataract* vs. } 272 \\
\text { with No Cataract } \dagger\end{array}$} & \multicolumn{4}{|c|}{$\begin{array}{l}\text { PSC } 194 \text { with Cataract* vs. } \\
272 \text { with No Cataract } †\end{array}$} \\
\hline & & OR $\ddagger$ & $95 \%$ CI & $P \mathbb{P}$ & $\boldsymbol{P} \|$ & OR $\ddagger$ & $95 \% \mathrm{CI}$ & $P \int$ & $\boldsymbol{P} \|$ & OR $\ddagger$ & $95 \% \mathrm{CI}$ & $P \int$ & $\boldsymbol{P} \|$ \\
\hline \multirow[t]{4}{*}{ Ascorbate } & 1 & 1 & & & & 1 & & & & 1 & & & \\
\hline & 2 & 0.57 & $0.36-0.90$ & 0.02 & 0.06 & 0.51 & $0.25-1.03$ & 0.1 & 0.1 & 0.53 & $0.36-0.78$ & 0.01 & 0.1 \\
\hline & 3 & 0.62 & $0.40-0.96$ & 0.04 & & 0.62 & $0.40-0.97$ & 0.04 & & 0.59 & $0.35-0.99$ & 0.05 & \\
\hline & $\log _{\mathrm{e}} \#$ & 0.85 & $0.71-1.03$ & 0.08 & & 0.83 & $0.70-0.97$ & 0.02 & & 0.86 & $0.71-1.04$ & 0.1 & \\
\hline \multirow[t]{4}{*}{ Lutein } & 1 & 1 & & & & 1 & & & & 1 & & & \\
\hline & 2 & 0.84 & $0.42-1.71$ & 0.6 & 0.3 & 0.75 & $0.46-1.23$ & 0.2 & 0.1 & 0.78 & $0.24-2.56$ & 0.6 & 0.4 \\
\hline & 3 & 0.75 & $0.44-1.31$ & 0.3 & & 0.53 & $0.28-1.02$ & 0.06 & & 0.72 & $0.30-1.71$ & 0.4 & \\
\hline & $\log _{e} \#$ & 0.76 & $0.59-0.99$ & 0.05 & & 0.67 & $0.50-0.90$ & 0.01 & & 0.85 & $0.56-1.31$ & 0.4 & \\
\hline \multirow[t]{4}{*}{ Zeaxanthin } & 1 & 1 & & & & 1 & & & & 1 & & & \\
\hline & 2 & 0.80 & $0.44-1.45$ & 0.4 & 0.2 & 0.72 & $0.33-1.57$ & 0.4 & 0.1 & 0.68 & $0.20-2.29$ & 0.5 & 0.6 \\
\hline & 3 & 0.71 & $0.43-1.17$ & 0.2 & & 0.58 & $0.30-1.12$ & 0.1 & & 0.84 & $0.43-1.67$ & 0.6 & \\
\hline & $\log _{e} \#$ & 0.76 & $0.63-0.93$ & 0.01 & & 0.76 & $0.57-1.02$ & 0.07 & & 0.90 & $0.63-1.27$ & 0.5 & \\
\hline \multirow{4}{*}{$\beta$-Cryptoxanthin } & 1 & 1 & & & & 1 & & & & 1 & & & \\
\hline & 2 & 0.68 & $0.35-1.33$ & 0.2 & 0.3 & 0.49 & $0.24-1.01$ & 0.1 & 0.9 & 0.72 & $0.28-1.84$ & 0.5 & 0.8 \\
\hline & 3 & 0.83 & $0.56-1.22$ & 0.3 & & 0.93 & $0.54-1.56$ & 0.7 & & 1.06 & $0.54-2.05$ & 0.9 & \\
\hline & $\log _{e} \#$ & 0.84 & $0.69-1.03$ & 0.1 & & 0.82 & $0.63-1.07$ & 0.1 & & 0.95 & $0.66-1.37$ & 0.8 & \\
\hline \multirow{4}{*}{$\alpha$-Carotene } & 1 & 1 & & & & 1 & & & & 1 & & & \\
\hline & 2 & 0.63 & $0.43-0.93$ & 0.03 & 0.2 & 0.45 & $0.27-0.75$ & 0.01 & 0.7 & 0.55 & $0.29-1.03$ & 0.1 & 0.6 \\
\hline & 3 & 0.74 & $0.48-1.14$ & 0.2 & & 0.86 & $0.60-1.22$ & 0.4 & & 0.80 & $0.39-1.65$ & 0.5 & \\
\hline & $\log _{\mathrm{e}} \#$ & 0.88 & $0.74-1.03$ & 0.1 & & 0.93 & $0.81-1.08$ & 0.3 & & 0.89 & $0.68-1.15$ & 0.3 & \\
\hline \multirow[t]{4}{*}{$\beta$-Carotene } & 1 & 1 & & & & 1 & & & & 1 & & & \\
\hline & 2 & 1.05 & $0.60-1.81$ & 0.9 & 0.2 & 1.07 & $0.51-2.26$ & 0.8 & 0.9 & 1.02 & $0.61-1.73$ & 0.9 & 0.4 \\
\hline & 3 & 0.75 & $0.44-1.26$ & 0.2 & & 1.02 & $0.52-1.99$ & 0.9 & & 0.71 & $0.30-1.68$ & 0.4 & \\
\hline & $\log _{e} \#$ & 0.85 & $0.74-0.98$ & 0.03 & & 0.93 & $0.76-1.13$ & 0.4 & & 0.88 & $0.63-1.23$ & 0.4 & \\
\hline \multirow[t]{4}{*}{ Lycopene } & 1 & 1 & & & & 1 & & & & 1 & & & \\
\hline & 2 & 1.13 & $0.67-1.91$ & 0.6 & 0.4 & 1.45 & $0.63-3.36$ & 0.3 & 0.7 & 0.98 & $0.49-1.98$ & 0.9 & 0.3 \\
\hline & 3 & 0.83 & $0.50-1.37$ & 0.4 & & 1.17 & $0.54-2.53$ & 0.7 & & 0.68 & $0.29-1.61$ & 0.3 & \\
\hline & $\log _{\mathrm{e}^{\#}}$ & 0.88 & $0.76-1.01$ & 0.06 & & 0.98 & $0.82-1.17$ & 0.8 & & 0.88 & $0.70-1.10$ & 0.2 & \\
\hline \multirow[t]{4}{*}{$\alpha$-Tocopherol } & 1 & 1 & & & 0.1 & 1 & & & 0.2 & 1 & & & \\
\hline & 2 & 0.97 & $0.66-1.42$ & 0.9 & & 0.77 & $0.44-1.33$ & 0.3 & & 1.32 & $0.75-2.31$ & 0.3 & 0.9 \\
\hline & 3 & 0.60 & $0.30-1.20$ & 0.1 & & 0.58 & $0.25-1.35$ & 0.2 & & 1.11 & $0.42-2.91$ & 0.8 & \\
\hline & $\log _{e} \#$ & 0.60 & $0.27-1.32$ & 0.2 & & 0.64 & $0.24-1.69$ & 0.3 & & 1.13 & $0.44-2.91$ & 0.8 & \\
\hline \multirow[t]{4}{*}{$\gamma$-Tocopherol } & 1 & 1 & & & & 1 & & & & 1 & & & \\
\hline & 2 & 1.58 & $0.98-2.51$ & 0.1 & 0.9 & 1.43 & $0.80-2.56$ & 0.2 & 0.5 & 1.23 & $0.64-2.37$ & 0.5 & 0.6 \\
\hline & 3 & 0.99 & $0.62-1.58$ & 0.9 & & 0.84 & $0.44-1.60$ & 0.5 & & 1.16 & $0.69-1.93$ & 0.5 & \\
\hline & $\log _{\mathrm{e}} \#$ & 1.06 & $0.56-2.02$ & 0.8 & & 0.83 & $0.45-1.55$ & 0.5 & & 1.47 & $0.80-2.67$ & 0.2 & \\
\hline \multirow[t]{4}{*}{$\alpha$-Tocopherol: cholesterol ratio } & 1 & 1 & & & & 1 & & & & 1 & & & \\
\hline & 2 & 0.82 & $0.51-1.31$ & 0.5 & 0.2 & 0.76 & $0.49-1.17$ & 0.2 & 0.5 & 1.14 & $0.65-2.02$ & 0.6 & 0.9 \\
\hline & 3 & 0.73 & $0.44-1.21$ & 0.2 & & 0.78 & $0.38-1.57$ & 0.4 & & 1.07 & $0.48-2.36$ & 0.9 & \\
\hline & $\log _{\mathrm{e}} \#$ & 0.62 & $0.34-1.15$ & 0.1 & & 0.72 & $0.32-1.62$ & 0.4 & & 1.06 & $0.43-2.63$ & 0.9 & \\
\hline \multirow[t]{4}{*}{$\gamma$-Tocopherol: cholesterol ratio } & 1 & 1 & & & & 1 & & & & 1 & & & \\
\hline & 2 & 1.35 & $0.93-1.97$ & 0.1 & 0.5 & 1.23 & $0.62-2.41$ & 0.5 & 0.8 & 0.95 & $0.59-1.52$ & 0.8 & 0.3 \\
\hline & 3 & 1.15 & $0.76-1.72$ & 0.5 & & 0.95 & $0.58-1.55$ & 0.8 & & 1.20 & $0.85-1.69$ & 0.3 & \\
\hline & $\log _{\mathrm{e}} \#$ & 1.15 & $0.68-1.95$ & 0.6 & & 0.94 & $0.50-1.76$ & 0.8 & & 1.39 & $0.79-2.44$ & 0.2 & \\
\hline \multirow[t]{4}{*}{ Retinol } & 1 & 1 & & & & 1 & & & 0.2 & 1 & & & \\
\hline & 2 & 0.74 & $0.45-1.06$ & 0.1 & 0.04 & 0.95 & $0.47-1.91$ & 0.9 & & 0.66 & $0.39-1.13$ & 0.1 & 0.2 \\
\hline & 3 & 0.56 & $0.33-0.96$ & 0.04 & & 0.69 & $0.38-1.26$ & 0.2 & & 0.69 & $0.39-1.23$ & 0.2 & \\
\hline & $\log _{\mathrm{e}} \#$ & 0.57 & $0.34-0.94$ & 0.03 & & 0.70 & $0.44-1.13$ & 0.1 & & 0.87 & $0.5-1.53$ & 0.6 & \\
\hline
\end{tabular}

* Cataract defined as LOCS II $\geq 2$.

† No cataract defined as LOCS II $<2$ on PSC, cortical and nuclear opacities, no dense opacities, and no history of surgery in either eye.

$\ddagger$ OR adjusted for age, sex, smoking, BMI, (weight in $\mathrm{kg} /(\text { height in } \mathrm{m})^{2}$, and average systolic blood pressure.

$\S P$ effect of each tertile compared with the lowest tertile.

$\| P$ for trend across tertiles.

\# $\log _{\mathrm{e}}$ modeled as the odds ratio for a doubling of the natural $\log$ of the antioxidant level.

We consider it unlikely that low levels of antioxidant vitamins, especially vitamin $\mathrm{C}$, in our sample were explained by problems in the collection, storage, and transport of the blood samples. Blood samples were collected in dim light (ascorbic acid may be degraded under bright light), refrigerated, and centrifuged with a cold centrifuge. Considerable care was taken to ensure that the samples remained under chilled conditions when transported back to the base hospital where they were frozen at $-80^{\circ} \mathrm{C}$. Samples were transported on dry ice with temperature monitoring to the central laboratory in Belfast and remained frozen at $-80^{\circ} \mathrm{C}$ until they were thawed for analysis. Moreover, the blood results show typical patterns observed in most other studies, such as a high correlation of lutein with zeaxanthin, higher levels of ascorbate in females than in males, and in never-smokers than in smokers, and a strong inverse association with age for many antioxidants. It is unlikely that these patterns would be preserved if the samples had degraded. 
Our results agree with evidence from in vitro studies of the role of antioxidants in the lens. ${ }^{21}$ Vitamin $\mathrm{C}$ is the most important antioxidant vitamin in the lens and found in the aqueous at concentrations of 30 - to 50 -fold that in plasma. ${ }^{22}$ The highly toxic reactive oxygen species that are formed by photochemical reactions of oxygen in the presence of electron donors are converted to less toxic hydrogen peroxide via ascorbic-acidmediated reduction. ${ }^{21,22}$ Lutein and zeaxanthin are the main carotenoids found in the lens, along with tocopherols, $\alpha$-carotene, lycopene, and retinol but very little $\beta$-carotene is present. $^{21,23}$ Although vitamin $C$ levels in our population were very low, we observed a significant reduced odds ratio of cataract above $6.5 \mu \mathrm{mol} / \mathrm{L}$ compared with levels below this cutoff. There was no additional benefit for those with blood levels above $15.4 \mu \mathrm{mol} / \mathrm{L}$. In contrast with our findings the U.S.-India case-control study reported an increased odds ratio for cataract associated with increasing plasma vitamin $\mathrm{C}$ although in other analyses an antioxidant index derived from glutathione peroxidase, ascorbic acid, vitamin $\mathrm{E}$, and glucose6-phosphate dehydrogenase was associated with a substantially reduced odds ratio for nuclear or PSC cataract $(\mathrm{OR}=0.12,95 \%$ CI $0.03-0.56) .{ }^{4}$ Observational studies conducted in Western populations of dietary or blood antioxidants have shown results which generally support the inverse association of vitamin $C$ with cataract although the evidence is not uniformly consistent. Significant inverse associations for plasma vitamin $\mathrm{C}$ have been reported from two studies in Europe. A study in Italy found that vitamin $\mathrm{C}$ levels of $\geq 65.5 \mu \mathrm{mol} / \mathrm{L}$ compared with $<30.5 \mu \mathrm{mol} / \mathrm{L}$ were associated with a reduced OR for nuclear $(\mathrm{OR}=0.54,95 \% \mathrm{CI} 0.30-0.97)$ and PSC cataract $(\mathrm{OR}=0.37,95 \%$ CI $0.15-0.93)$ but not with cortical cataract. ${ }^{24}$ A Spanish case-control study found a reduced OR for cataract for vitamin $\mathrm{C}>49 \mu \mathrm{mol} / \mathrm{L}$ compared with $\leq 49$ $\mu \mathrm{mol} / \mathrm{L}(\mathrm{OR}=0.32,95 \% \mathrm{CI} 0.21-0.51) .{ }^{25}$ In both these studies, vitamin $\mathrm{C}$ was substantially higher than in our study. In contrast, no association was reported in two other European studies, although in both those studies ${ }^{26,27}$ the levels of vitamin $\mathrm{C}$ were lower than in the studies just earlier in the paragraph. Positive associations for a protective effect of blood measures of vitamin $\mathrm{C}$ have also been reported in some observational studies in the United States, ${ }^{28,29}$ but not in all. ${ }^{30}$ Studies in which dietary measures of antioxidants were used mainly reported a positive protective association, ${ }^{31-34}$ but others showed no association. ${ }^{35,36}$

We found an inverse association with zeaxanthin or lutein and cataract. Other studies have shown inverse associations with serum lutein or zeaxanthin with cataract ${ }^{27,37,38}$ or no association with any type of cataract. ${ }^{25,39}$ The evidence for dietary intake of lutein and zeaxanthin has been inconsistent. A recent substantive review concluded that there is insufficient evidence to support a benefit from lutein or zeaxanthin on risk of cataract. ${ }^{40}$ We found a significant association for $\alpha$ - and $\beta$-carotene, but several studies have found no association with dietary or plasma $\alpha$ - or $\beta$-carotene. ${ }^{41,42}$ Plasma $\beta$-carotene was associated with reduced nuclear opacities in two studies in Northern Europe, ${ }^{27,43}$ but not for several others in diverse Western countries. ${ }^{24,25,30}$

We found an inverse association for increasing retinol and cataract. The Blue Mountains Eye Study and POLA (Pathologies Oculaires Liées à L'Age) study also reported protective associations for dietary ${ }^{44}$ or plasma vitamin $\mathrm{A},{ }^{26}$ but other studies have reported either no association ${ }^{32,42,45,46}$ or a U-shaped relationship with plasma retinol. ${ }^{25,30}$ The evidence of a protective effect of vitamin E measured in the serum is stronger with inverse associations reported for incident cataract in the Beaver Dam Eye Study, ${ }^{41}$ with prevalent nuclear, but not cortical cataract in the Salisbury Eye study, ${ }^{30}$ with both prevalent and incident nuclear cataract in the U.S.-based Lens Opacities
Case-Control Study, ${ }^{47,48}$ and in two studies in Finland: a nested case control study of cataract ${ }^{43}$ and of progression of cortical, but not nuclear, lens opacities in hypercholesterolemic males. ${ }^{49}$ In other studies, no association ${ }^{25,27}$ or an increased risk with high serum vitamin $\mathrm{E}$ has been reported. ${ }^{24}$ We found no association for the ratio of $\alpha$ - or $\gamma$-tocopherol to cholesterol.

We measured antioxidants in the blood. There are several advantages of blood measurements. They provide an objective measurement of antioxidant status and are not subject to usual problems of diet questionnaires such as recall or biased responses. Calculating dietary antioxidant intake from diet questionnaires requires appropriate food composition tables and information on portion sizes and methods of cooking that may be additional sources of error. In our study, blood measurements were the only marker of antioxidant intake available, since there is very limited information on antioxidants in the Indian food composition tables. Diet and supplements are the main determinants of blood antioxidant levels. In our study, supplement use was less than $0.1 \%$ in contrast to studies in Western populations, where at least a third of the adult population use multivitamin supplements regularly. ${ }^{50}$ Thus, blood antioxidants in our population are primarily markers for dietary intakes in contrast to Western populations where supplements as well as diet influence blood levels.

Our study was cross sectional, and we cannot exclude the possibility of reverse causation (i.e., a change in diet because of knowledge of cataract). In our population setting, with a high proportion of illiterate people, it is unlikely that people would have changed their diet for this reason. Most people in the study were unaware of their diagnosis and in general there is little, if any, knowledge about the possible role of a high antioxidant diet in cataract prevention in rural populations in India. The study was conducted over the winter, and the blood antioxidants may not reflect the usual diet over the year, when taking seasonal variation into account. However, dietary variation should not lead to a bias in the odds ratios, since blood was collected from those with and without cataract over the same period. We did not collect information on diabetes, an established risk factor for cataract in Western populations. ${ }^{2}$ No participants reported taking medication for diabetes, but it is unlikely that in this population many people would have been tested for diabetes. It is possible that our population was also protein deficient, but we had no information on protein intake or protein-related biochemical measures. Although studies have been conducted in populations that are not protein deficient, associations have been observed with opacities and low levels of protein or markers of low protein, ${ }^{47,51}$ but these studies also reported an inverse association with antioxidant measures, indicating that low protein intake did not confound the association.

In both our study and in a study in south India, the prevalence of cataract (defined either as lens opacities or cataract surgery) was considerably higher than in Western countries. ${ }^{915}$ In particular, the prevalence of PSC opacities was much higher than in Western populations. Analyses by type of cataract did not indicate any major differences in the pattern of associations, although the evidence was strongest for vitamin C, lutein, zeaxanthin, and retinol. The high prevalence of nuclear cataract and the fact that most cataracts were mixed made it difficult to assess whether there are real differences in the influence of nutritional factors on the subtypes.

Randomized trials have evaluated whether the incidence or progression of cataract may be delayed by supplementation. The trials in Western populations have shown negative results for single vitamin supplements and mixed results with multivitamin supplements. ${ }^{52-54}$ There was no benefit from a highdose multivitamin supplement (vitamins $\mathrm{C}$ and $\mathrm{E}$ and $\beta$-carotene) in the Age-Related Eye Disease Study. ${ }^{54}$ As $67 \%$ of the 
control arm and $65 \%$ of the intervention arm were also taking a low-dose, broad-spectrum multivitamin and mineral supplement (Centrum, Wyeth Laboratories, Madison, NJ), it is possible that there was no additional benefit from the high-dose supplement. A recently published trial in an Italian population found a reduced rate of progression of nuclear opacities with a broad-spectrum multivitamin/mineral supplement after an average of 9 years of supplement use. ${ }^{53}$ However, this trial also found an increased risk of PSC. ${ }^{53}$ The two Linxian trials were performed in a nutritionally deficient rural Chinese population and were designed to examine the effects of various supplements on esophageal cancer. ${ }^{13}$ An end-of-trial eye examination was conducted. Of the two trials, one trial in people with esophageal dysplasia found no overall benefit from the vita$\mathrm{min} / \mathrm{mineral}$ supplement $(\mathrm{OR}=0.80,95 \% \mathrm{CI} 0.57-1.12)$ although a significant reduction was reported for those aged 65 to 74 years $(\mathrm{OR}=0.57,95 \% \mathrm{CI} 0.36-0.90)$. The second trial was a factorial trial of four different vitamin or mineral combinations. A reduced prevalence of cataract was observed with riboflavin and niacin, whereas the ORs for retinol and zinc or vitamin $\mathrm{C}$ and molybdenum were in the direction of benefit, although the $95 \%$ CIs just crossed unity. There was no benefit from the combination of selenium, $\alpha$-tocopherol, and $\beta$-carotene. The trial in southern India found no benefit from supplementation with multivitamins (vitamins $\mathrm{A}, \mathrm{C}$, and $\mathrm{E}$ ) on the rate of progression of opacities over a 5-year period using clinical grading at the slit lamp. ${ }^{14}$ That study had no information on the antioxidant status of participants and did not include lutein and zeaxanthin, which we found to be associated with cataract. There is a debate over whether differences in trial results relate to factors such as dose or length of follow-up, incidence or progression of cataract, a broad-spectrum supplement versus supplementation with a few antioxidants, and the lack of any trials evaluating lutein and zeaxanthin. ${ }^{55}$ The vitamin/mineral supplement (Centrum; Wyeth Laboratories) contains antioxidant vitamins given at recommended daily intakes including A, $\mathrm{E}$, and $\mathrm{C}$; the $\mathrm{B}$ complex vitamins; folic acid; and vitamin $\mathrm{D}$; and minerals, such as zinc and copper. It can only be speculated as to whether the benefit of the vitamin/mineral supplement on nuclear opacities in the Italian trial was due to the synergistic effects of some or all of the vitamins and minerals or to specific effects of certain individual vitamins, or why the vitamin/ mineral formulation was associated with an adverse effect on PSC. Lutein and zeaxanthin supplements are currently being evaluated in the AREDS 2 trial. (http://www.areds2.org/).

Our results showed associations with vitamin $\mathrm{C}$ and the carotenoids (lutein, zeaxanthin, carotenes, and lycopene). Because blood measurements of these antioxidants are markers of fruit and vegetable intake it is possible that the associations we observed reflect other micronutrients in fruit and vegetables such as flavonoids and folate. Currently, there are limited data on these micronutrients in the etiology of lens opacities.

It is plausible that the high levels of cataract in the rural Indian population are due in part to high levels of UVR exposure and antioxidant-depleted diets (as shown by the blood levels in our study). Our study provides some evidence to support this hypothesis, although our cross-sectional study design warrants caution. A larger study is now under way in both north and south India.

\section{Acknowledgments}

The authors thank the field teams and administrative staff at the Department of Community Ophthalmology, Dr. Rajendra Prasad Centre, All India Institute of Medical Sciences, Delhi; Jayne Woodside and Sarah Parrish, Queen's University Belfast, who conducted the laboratory analyses; and Vittorio Silvestri for assistance with setting up and training in lens and fundus photography.

\section{References}

1. Resnikoff S, Pascolini D, Etya'ale D, et al. Global data on visual impairment in the year 2002. Bull World Health Organ. 2004;82: 844-851.

2. Robman L, Taylor H. External factors in the development of cataract. Eye. 2005;19:1074-1082.

3. Sreenivas V, Prabhakar AK, Badrinath SS, et al. A rural population based case-control study of senile cataract in India. J Epidemiol. 1999;9:327-336.

4. Mohan M, Sperduto RD, Angra SK, et al. India-US case-control study of age-related cataracts. India-US Case-Control Study Group. Arch Ophthalmol. 1989;107:670-676.

5. Krishnaiah S, Vilas K, Shamanna BR, Rao GN, Thomas R, Balasubramanian D. Smoking and its association with cataract: results of the Andhra Pradesh eye disease study from India. Invest Ophthalmol Vis Sci. 2005;46:58-65.

6. Nirmalan PK, Robin AL, Katz J, et al. Risk factors for age related cataract in a rural population of southern India: the Aravind Comprehensive Eye Study. Br J Ophthalmol. 2004;88:989-994.

7. Pokhrel AK, Smith KR, Khalakdina A, Deuja A, Bates MN. Casecontrol study of indoor cooking smoke exposure and cataract in Nepal and India. Int J Epidemiol. 2005;34:702-708.

8. Raju P, George R, Ve Ramesh S, Arvind H, Baskaran M, Vijaya L. Influence of tobacco use on cataract development. Br J Ophthalmol. 2006;90:1374-1377.

9. Murthy GV, Gupta SK, Maraini G, et al. Prevalence of lens opacities in North India: the INDEYE feasibility study. Invest Ophthalmol Vis Sci. 2007; 48:88-95.

10. Chylack LT Jr, McCarthy LM, Khu DP, Kashiwagi T, Sperduto R. Lens opacities classification system II (LOCS II). Arch Ophthalmol. 1989;107:991-997.

11. WHO Expert Consultation. Appropriate body-mass index for Asian populations and its implications for policy and intervention strategies (published correction in 2004:13;363:902). Lancet. 2004; 363:157-163.

12. StataCorp. Stata Statistical Software: Release 9.0. College Station, TX: Stata Corp.; 2005.

13. Sperduto RD, Hu TS, Milton RC, et al. The Linxian cataract studies: two nutrition intervention trials. Arch Ophthalmol. 1993;111: 1246-1253.

14. Gritz DC, Srinivasan M, Smith SD, et al. The antioxidants in prevention of cataracts study: effects of antioxidant supplements on cataract progression in South India. Br J Ophthalmol. 2006;90: 847-851.

15. Nirmalan PK, Krishnadas R, Ramakrishnan R, et al. Lens opacities in a rural population of southern India: the Aravind Comprehensive Eye Study. Invest Ophthalmol Vis Sci. 2003;44:4639-4643.

16. Olmedilla B, Granado F, Southon S, et al. Serum concentrations of carotenoids and vitamins $\mathrm{A}, \mathrm{E}$, and $\mathrm{C}$ in control subjects from five European countries. BrJ Nutr. 2001;85:227-238.

17. Chiplonkar SA, Agte VV, Mengale SS, Tarwadi KV. Are lifestyle factors good predictors of retinol and vitamin $C$ deficiency in apparently healthy adults? Eur J Clin Nutr. 2002;56:96-104.

18. Hughes $\mathrm{K}$, New AL, Lee BL, Ong CN. Plasma vitamins A, C and E in the general population of Singapore, 1993 to 1995. Ann Acad Med Singapore. 1998;27:149-153.

19. Al-Delaimy WK, van Kappel AL, Ferrari P, et al. Plasma levels of six carotenoids in nine European countries: report from the European Prospective Investigation into Cancer and Nutrition (EPIC). Public Health Nutr. 2004;7:713-722.

20. Faure H, Preziosi P, Roussel AM, et al. Factors influencing blood concentration of retinol, alpha-tocopherol, vitamin C, and betacarotene in the French participants of the SU.VI.MAX trial. Eur J Clin Nutr. 2006;60:706-717.

21. Taylor A, Hobbs M. 2001 assessment of nutritional influences on risk for cataract. Nutrition. 2001;17:845-857.

22. Varma SD. Ascorbic acid and the eye with special reference to the lens. Ann N Y Acad Sci. 1987;498:280-306.

23. Bernstein PS, Khachik F, Carvalho LS, Muir GJ, Zhao DY, Katz NB. Identification and quantitation of carotenoids and their metabolites in the tissues of the human eye. Exp Eye Res. 2001;72:215223. 
24. Ferrigno L, Aldigeri R, Rosmini F, Sperduto RD, Maraini G. Associations between plasma levels of vitamins and cataract in the Italian-American Clinical Trial of Nutritional Supplements and AgeRelated Cataract (CTNS): CTNS Report \#2. Opbthalmic Epidemiol. 2005;12:71-80.

25. Valero MP, Fletcher AE, De Stavola BL, Vioque J, Alepuz VC. Vitamin $C$ is associated with reduced risk of cataract in a Mediterranean population. $J$ Nutr. 2002;132:1299-1306.

26. Delcourt C, Cristol JP, Tessier F, Leger CL, Michel F, Papoz L. Risk factors for cortical, nuclear, and posterior subcapsular cataracts: the POLA study. Pathologies Oculaires Liees a l'Age. Am J Epidemiol. 2000;151:497-504.

27. Gale CR, Hall NF, Phillips DI, Martyn CN. Plasma antioxidant vitamins and carotenoids and age-related cataract. Ophthalmology. 2001;108:1992-1998.

28. Jacques PF, Chylack LT Jr. Epidemiologic evidence of a role for the antioxidant vitamins and carotenoids in cataract prevention. Am J Clin Nutr. 1991;53:352S-355S.

29. Simon JA, Hudes ES. Serum ascorbic acid and other correlates of self-reported cataract among older Americans. J Clin Epidemiol. 1999;52:1207-1211.

30. Vitale S, West S, Hallfrisch J, et al. Plasma antioxidants and risk of cortical and nuclear cataract. Epidemiology. 1993;4:195-203.

31. Jacques PF, Chylack LT Jr, Hankinson SE, et al. Long-term nutrient intake and early age-related nuclear lens opacities. Arch Ophthalmol. 2001;119:1009-1019.

32. Leske MC, Chylack LT Jr, Wu SY. The Lens Opacities Case-Control Study: risk factors for cataract. Arch Opbthalmol. 1991;109:244251.

33. Taylor A, Jacques PF, Chylack LT Jr, et al. Long-term intake of vitamins and carotenoids and odds of early age-related cortical and posterior subcapsular lens opacities. Am J Clin Nutr. 2002;75:540549.

34. Lyle BJ, Mares-Perlman JA, Klein BE, Klein R, Greger JL. Antioxidant intake and risk of incident age-related nuclear cataracts in the Beaver Dam Eye Study. Am J Epidemiol. 1999;149:801-809.

35. Tavani A, Negri E, La Vecchia C. Food and nutrient intake and risk of cataract. Ann Epidemiol. 1996;6:41-46.

36. Hankinson SE, Stampfer MJ, Seddon JM, et al. Nutrient intake and cataract extraction in women: a prospective study. BMJ. 1992;305: 335-339.

37. Moeller SM, Voland R, Tinker L, et al. Associations between agerelated nuclear cataract and lutein and zeaxanthin in the diet and serum in the carotenoids in the Age-Related Eye Disease Study (CAREDS), an ancillary study of the Women's Health Initiative. Arch Ophthalmol. 2008;126:354-364.

38. Delcourt C, Carriere I, Delage M, Barberger-Gateau P, Schalch W. Plasma lutein and zeaxanthin and other carotenoids as modifiable risk factors for age-related maculopathy and cataract: the POLA Study. Invest Opbthalmol Vis Sci. 2006;47:2329-2335.
39. Mares-Perlman JA, Brady WE, Klein BE, et al. Serum carotenoids and tocopherols and severity of nuclear and cortical opacities. Invest Ophthalmol Vis Sci. 1995;36:276-288.

40. Trumbo PR, Ellwood KC. Lutein and zeaxanthin intakes and risk of age-related macular degeneration and cataracts: an evaluation using the Food and Drug Administration's evidence-based review system for health claims. Am J Clin Nutr. 2006;84:971-974.

41. Lyle BJ, Mares-Perlman JA, Klein BE, et al. Serum carotenoids and tocopherols and incidence of age-related nuclear cataract. $A m J$ Clin Nutr. 1999;69:272-277.

42. Brown L, Rimm EB, Seddon JM, et al. A prospective study of carotenoid intake and risk of cataract extraction in US men. Am J Clin Nutr. 1999;70:517-524.

43. Knekt P, Heliovaara M, Rissanen A, Aromaa A, Aaran RK. Serum antioxidant vitamins and risk of cataract. BMJ. 1992;305:13921394.

44. Cumming RG, Mitchell P, Smith W. Diet and cataract: the Blue Mountains Eye Study. Ophthalmology. 2000;107:450-456.

45. Jacques PF, Chylack LT Jr, McGandy RB, Hartz SC. Antioxidant status in persons with and without senile cataract. Arch Opbthalmol. 1988; 106:337-340.

46. Chasan-Taber L, Willett WC, Seddon JM, et al. A prospective study of carotenoid and vitamin A intakes and risk of cataract extraction in US women. Am J Clin Nutr. 1999;70:509-516.

47. Leske MC, Wu SY, Hyman L, et al. Biochemical factors in the lens opacities; case-control study. The Lens Opacities Case-Control Study Group. Arch Ophthalmol. 1995;113:1113-1119.

48. Leske MC, Chylack LT Jr, He Q, et al. Antioxidant vitamins and nuclear opacities: the longitudinal study of cataract. Ophthalmology. 1998;105:831-836.

49. Rouhiainen $\mathrm{P}$, Rouhiainen $\mathrm{H}$, Salonen JT. Association between low plasma vitamin E concentration and progression of early cortical lens opacities. Am J Epidemiol. 1996;144:496-500.

50. Rock CL. Multivitamin-multimineral supplements: who uses them? Am J Clin Nutr. 2007;85:277S-279S.

51. Delcourt C, Dupuy AM, Carriere I, Lacroux A, Cristol JP. Albumin and transthyretin as risk factors for cataract: the POLA study. Arch Opbthalmol. 2005;123:225-232.

52. Seddon JM. Multivitamin-multimineral supplements and eye disease: age-related macular degeneration and cataract. Am J Clin Nutr. 2007;85:304S-307S.

53. Clinical Trial of Nutritional Supplements and Age-Related Cataract. A randomized, double-masked, placebo-controlled clinical trial of multivitamin supplementation for age-related lens opacities. Report No. 3. Ophthalmology. 2008;115:599-607.e1.

54. A randomized, placebo-controlled, clinical trial of high-dose supplementation with vitamins $\mathrm{C}$ and $\mathrm{E}$ and beta carotene for agerelated cataract and vision loss: AREDS report no. 9. Arch Ophthalmol. 2001;119:1439-1452.

55. Chong EW, Wong TY. Multivitamin supplements and cataract prevention. Ophthalmology. 2008;115:597-598. 